\title{
UMA ANÁLISE DO COMÉRCIO BILATERAL BRASIL-CHINA: A DETERIORAÇÃO DOS TERMOS DE TROCA E O CASO DA SOJA
}

\author{
Tomás Costa de Azevedo Marques ${ }^{1}$ \\ Reinaldo Campos $^{2}$
}

\begin{abstract}
Durante a primeira década dos anos 2000, a América Latina viveu o chamado boom das commodities, causado principalmente pela alta demanda chinesa por bens primários. Isso levou a região a apresentar altas taxas de crescimento e garantiu superavit na balança comercial, estreitando os laços desses países com a República Popular da China (RPC). No entanto, sem mudanças estruturais significativas, a região manteve sua posição de exportadora de bens primários na divisão internacional do trabalho e, a partir de 2011, começou a perder seu dinamismo. Este artigo busca analisar esse fenômeno no século XXI a partir do comércio bilateral entre Brasil e RPC, destacando a importância da soja nesse contexto e suas implicações estratégicas e econômicas. Isso é feito com base em uma revisão da tese Prebisch-Singer e sua relevância dentro das cadeias globais de valor (CGVs) no século XXI. O objetivo é compreender a deterioração dos termos de troca entre Brasil e RPC, bem como a especialização regressiva do Brasil, enquanto a estratégia chinesa concentra-se em importar o produto de baixo valor agregado e gerar valor internamente, utilizando como base da sua cadeia de produção e consumo no âmbito de um projeto de desenvolvimento a médio-longo prazo.
\end{abstract}

Palavras-chave: Brasil-China; comércio bilateral; Prebisch-Singer; deterioração dos termos de troca; CGVs.

\section{AN ANALYSIS OF BRAZIL-CHINA BILATERAL TRADE: THE DETERIORATION OF TERMS OF TRADE AND THE CASE OF SOYBEAN}

During the first decade of the 2000s, Latin America experienced the so-called commodities boom mainly caused by the high Chinese demand for primary goods. This led the region to present high growth rates and it provided a surplus in the trade balance, strengthening the ties of these countries with the People's Republic of China (PRC). However, without significant structural changes, Latin America maintained its position as an exporter of primary goods in the international division of labor, and from 2011 it began to lose its dynamism. This article seeks to analyze this phenomenon in the 21st century based on the bilateral trade between Brazil and the PRC, highlighting the importance of soybean trade in this context and its strategic and economic implications. This is analyzed through a review of the Prebisch-Singer thesis and its relevance within the global value chains in the $21 \mathrm{st}$ century. The purpose of the article is to understand the deterioration of the terms of trade between Brazil and the PRC, as well as the regressive specialization of Brazil, while the Chinese strategy focuses on importing the low value-added product and generating value internally, using it as the basis of its production and consumption as part of a medium-long term development project.

Keywords: Brazil-China; bilateral trade; Prebisch-Singer; Deterioration of terms of trade; Global value chains (GVC).

1. Doutorando em economia política mundial pela Universidade Federal do $A B C$ (UFABC); e mestre em integração da América Latina pela Universidade de São Paulo (USP).E-mail: <tomas.marques@ufabc.edu.br>. Orcid: <https://orcid.org/0000-0001-8713-7453>.

2. Doutorando em economia política mundial pela Universidade Federal do $A B C$ (UFABC); e mestre em desenvolvimento econômico pela Universidade Federal do Paraná (UFPR).E-mail: <reinaldo.campos@embrapa.br>. Orcid: <https://orcid.org/0000-0001-8612-6672>. 


\section{ANÁLISIS DEL COMERCIO BILATERAL BRASIL-CHINA: EL DETERIORO DE LOS TÉRMINOS DE CAMBIO Y EL CASO DE LA SOJA}

Durante la primera década de la década de 2000, América Latina experimentó el llamado boom de las materias primas causado principalmente por la alta demanda china de bienes primarios. Esto llevó a la región a mostrar altas tasas de crecimiento y garantizó un superavit en la balanza comercial, fortaleciendo los vínculos de estos países con la República Popular China (RPC). Sin embargo, sin cambios estructurales significativos, la región mantuvo su posición como exportadora de bienes primarios en la división internacional del trabajo, y a partir de 2011 comenzó a perder su dinamismo. Este artículo busca analizar este fenómeno en el siglo XXI a partir del comercio bilateral entre Brasil y la República Popular China, destacando la importancia de la soja en este contexto y sus implicaciones estratégicas y económicas. Esto se hace a través de una revisión de la tesis de Prebisch-Singer y su relevancia dentro de las cadenas de valor globales (CVGs) en el siglo XXI. El objetivo es comprender el deterioro de los términos de intercambio entre Brasil y la República Popular China, así como la especialización regresiva de Brasil, mientras que la estrategia china se enfoca en importar el producto de bajo valor agregado y generar valor internamente, utilizando la base de su cadena de suministro producción y consumo como parte de un proyecto de desarrollo a medio-largo plazo.

Palabras clave: Brasil-China; comercio bilateral; Prebisch-Singer; deterioro de los términos de intercambio; CVGs.

JEL: F14; Q17; 011.

DOI: http://dx.doi.org/10.38116/rtm24art13

Data de envio do artigo: 31/8/2020. Data de aceite: 4/11/2020.

\section{INTRODUÇÃO}

Um dos principais marcos da história recente da economia mundial foi a ascensão da República Popular da China (RPC) como a segunda maior economia no século XXI. Destacam-se, nessa complexa trajetória, as reformas modernizantes lideradas por Deng Xiaoping em 1978, a política de atração de Investimento Direto Externo (IDE) nos anos 1990 e o ingresso do país na Organização Mundial do Comércio (OMC) em 2001. Esses fatos são determinantes na integração controlada da RPC na economia internacional, o que fez com que o país conseguisse se inserir de forma efetiva nas cadeias globais de valor (CGVs), além de promover a internacionalização de suas empresas.

Nesse contexto, a América Latina, como uma regiáo periférica tradicionalmente fornecedora de bens primários, foi beneficiada pela alta demanda da RPC pelas commodities. Após uma década de deficit nas balanças comerciais, a regiáo passou a registrar superavit expressivos na maior parte dos seus países na primeira década dos anos 2000. Como sugere Gruss (2014, p. 3-4), tal fenômeno, conhecido pelo boom das commodities, foi um dos responsáveis pelas altas taxas de crescimento da economia dos países latino-americanos, que quase dobrou no período 2003-2011 (4\%) comparado a 1980-2002 (2,5\%); e esse aumento dos 
preços, e não o seu nível, ou seja, a variação positiva, apresenta uma correlação com o crescimento do produto interno bruto (PIB) dos países na América Latina (Gruss, 2014, p. 9-10). No entanto, a partir de 2012, é possível notar o início da desaceleração do índice de preços, puxado inicialmente por commodities não petrolíferas, que, a partir de 2014, apresentam uma queda abrupta pela variação negativa no preço do petróleo (Ocampo, 2017, p. 63). Além disso, também houve uma desaceleração do crescimento chinês, que passou de uma média de 7,1\%, no período 2012-2019, ante 10,3\% entre 2003 e 2011.

GRÁFICO 1

Índice de preços de commodities excluindo ouro de 1992-2020

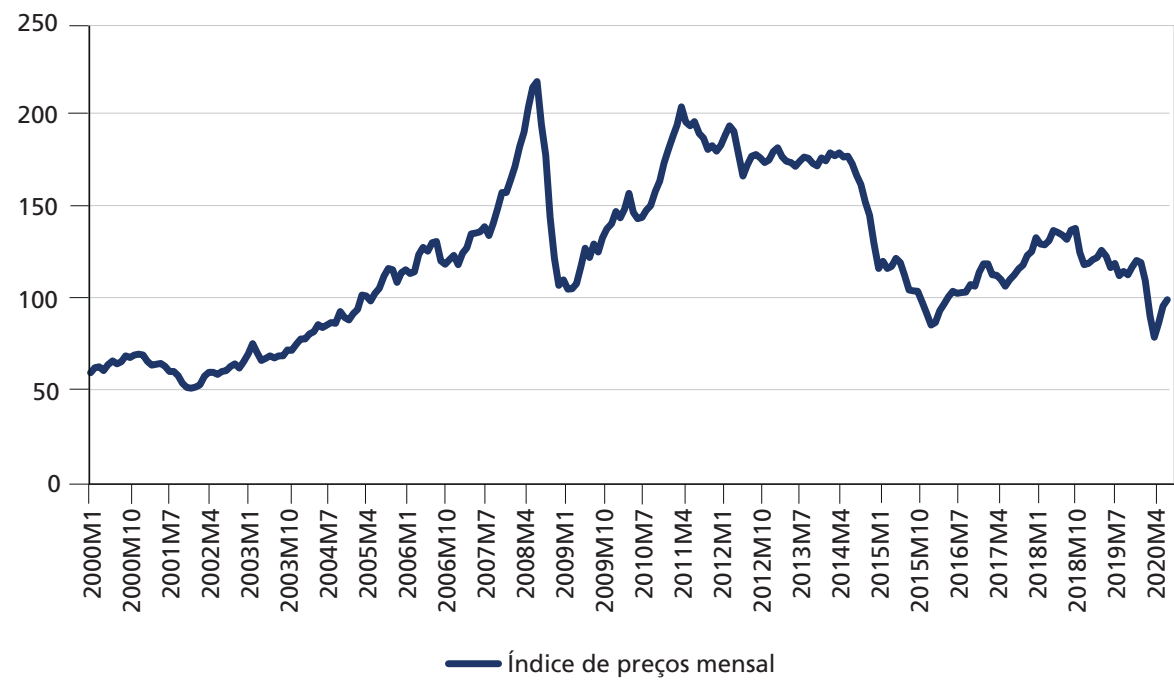

Fonte: IMF (2020). Disponível em: <https://www.imf.org/en/Research/commodity-prices>

Elaboração dos autores.

Nota: ${ }^{1}$ Até julho de 2020

Obs.: $2016=100$.

A variação dos preços das commodities no período de 2003 a 2014, com uma pequena interrupção em 2009, evidenciada no gráfico 1, pode ser considerada uma quebra estrutural da séria histórica, assim como ocorre nos anos 1950, com o processo de retomada do crescimento da economia europeia pós-Segunda Guerra, e nos anos 1970, com o choque dos preços do petróleo. No entanto, diferentemente dos períodos anteriores, o período de alta apresentou uma duração mais prolongada. Foi justamente nesse contexto que a RPC se tornou o principal parceiro comercial dos países da América Latina. Ao mesmo tempo, além de importar commodities, também ganhou participação no sentido inverso, exportando manufaturados de média e alta tecnologia e realizando investimentos diretos em setores estratégicos para seu abastecimento, como petróleo, agricultura, 
minas e energia, por meio de aquisiçóes nacionais e internacionais, como também, em menor escala, com novos investimentos.

Quando observado o comércio bilateral entre os países da América Latina e a RPC, é possível constatar que, dos anos 2000 para 2018, houve uma grande mudança de cenário para ambos os lados. No início do século, a RPC era um destino de pouca relevância para a grande maioria dos países da região, tendo a maior participação como destino das exportaçóes do Peru, de 7,5\%. Enquanto origem das importaçóes de países latino-americanos, a RPC também tinha pouca importância, com maior entrada no Panamá, com aproximadamente 7,5\% nas importaçóes do país. Em menos de duas décadas depois, a RPC passou a figurar entre os três principais parceiros da região, se não o principal - posição antes ocupada pelos Estados Unidos. Sua participação tanto no destino como na origem cresceu mais de dez vezes em diversos países, com destaque para a Colômbia, cujas exportaçóes para a RPC cresceram mais de cinquenta vezes, e para a Bolívia, cujas importaçóes da China cresceram mais de vinte vezes.

TABELA 1

Participação e posição da China no valor total das exportações e importações (2000 e 2018)

\begin{tabular}{|c|c|c|c|c|c|c|c|c|}
\hline \multirow{3}{*}{ País } & \multicolumn{4}{|c|}{ Exportações para a RPC } & \multicolumn{4}{|c|}{ Importações de origem da RPC } \\
\hline & \multicolumn{2}{|c|}{ Participação (\%) } & \multicolumn{2}{|c|}{ Posição } & \multicolumn{2}{|c|}{ Participação (\%) } & \multicolumn{2}{|c|}{ Posição } \\
\hline & 2000 & 2018 & 2000 & 2018 & 2000 & 2018 & 2000 & 2018 \\
\hline Argentina & 3 & 6,5 & 6 & 3 & 3,1 & 14,1 & 8 & 3 \\
\hline Bolívia & 0,9 & 4,1 & 17 & 9 & 0,5 & 11,6 & 19 & 3 \\
\hline Brasil & 2 & 27 & 12 & 1 & 2,1 & 18,9 & 10 & 2 \\
\hline Chile & 5,8 & 31,5 & 4 & 1 & 4,6 & 22,1 & 5 & 1 \\
\hline Colômbia & 0,2 & 10,6 & 30 & 2 & 1,8 & 17,7 & 15 & 2 \\
\hline Costa Rica & 0,2 & 4,6 & 32 & 3 & 1,2 & 11 & 17 & 2 \\
\hline Equador & 1,2 & 7,5 & 20 & 3 & 2,1 & 16,7 & 12 & 2 \\
\hline México & 0,2 & 2,4 & 17 & 3 & 1,1 & 10,6 & 8 & 2 \\
\hline Panamá & 0,1 & 1,7 & 73 & 12 & 7,5 & 16,1 & 3 & 1 \\
\hline Peru & 7,5 & 26,5 & 3 & 1 & 2,4 & 20,7 & 13 & 2 \\
\hline Uruguai & 3,4 & 21,8 & 6 & 1 & 5,5 & 17,5 & 4 & 2 \\
\hline Venezuela & 0,2 & 20,5 & 33 & 3 & 1,6 & 9,8 & 14 & 2 \\
\hline
\end{tabular}

Fonte: UN Comtrade (2020).

Elaboração dos autores.

Obs.: 1. Participação em valor do total da balança comercial (produtos e serviços).

2. Os dados da Comtrade separam Hong Kong da China.

3. O Paraguai não foi incluso porque possui relações diplomáticas com Taiwan e, por isso, tem inexpressiva relação comercial formal com a China.

Os dados mostram que a participação da região no valor de importaçóes chinesas passou de 1,92\% para 7\% entre 2000 e 2018, sendo que 54,12\% delas 
são de origem brasileira. ${ }^{3}$ Apesar de a América Latina ainda ter participação pequena no valor das importaçóes chinesas, representa um aumento de mais de três vezes. Nesse sentido, Medeiros e Cintra (2015, p. 35-37) destacam que tais importaçóes concentram-se em poucas commodities, como a soja (Brasil e Argentina), a madeira (Chile), o minério de ferro (Brasil) e o petróleo (Venezuela e Brasil). Entretanto, a participação da regiấo como destino das exportações chinesas também triplicou, passando de $1,2 \%$ para $3,34 \%{ }^{4}$ no mesmo período, sendo os principais produtos de média e alta tecnologia (Bernal-Meza, 2016, p. 30-32). Mesmo nessa mudança de cenário, em que a China passa a ganhar grande importância na região, vale relembrar que historicamente a América Latina sempre ocupou essa posição de exportadora de bens primários e importadora de manufaturados dentro da divisão internacional do trabalho.

Assim, a RPC consolidou sua presença na América Latina em relativamente pouco tempo. Porém, mesmo que isso tenha gerado um efeito positivo no crescimento econômico desses países por meio da valorização dos preços das commodities, é necessário refletir sobre o impacto dessa posição da região, enquanto exportadora de produtos primários e importadora de manufaturados em uma perspectiva histórica, além do fato de que, entre os países que comercializam com a China, apenas Brasil, Chile, Peru e Venezuela mantiveram superavit comercial em 2018.

Diante disso, este trabalho tem como objetivo analisar como as relaçóes comerciais da RPC com o Brasil acabaram por determinar um padrão de produção agrícola no Brasil que privilegia, cada vez mais, a produçáo de culturas como a soja, que apresenta uma forte integração nas cadeias produtivas internacionais. Nossa hipótese é de que esse padrão de expansão comercial brasileira não tem sido suficiente para minorar a deterioração nos termos de troca, uma vez que o país se especializa em commodities, e a RPC, em produtos de maior valor agregado. A análise é feita a partir de uma abordagem histórico-estrutural, ${ }^{5}$ que compreende o desenvolvimento como um processo histórico em uma economia mundial hierarquizada entre centro e periferia. Assim, é observada a evolução dos termos de troca a partir do modelo Prebisch-Singer no contexto das CGVs.

Buscamos avançar nas pesquisas de Andrade, Naretto e Leite (2015), Black (2016), Medeiros e Cintra (2015) e Pella (2019); além de atualizar os dados, analisamos os termos de troca do comércio bilateral entre Brasil-China e a importância estratégica da soja brasileira para a RPC como um estudo de caso. O artigo está dividido em quatro partes, além desta contextualizaçâo inicial. Na segunda

3. Disponivel em: <https://atlas.cid.harvard.edu/explore>.

4. Disponível em: <https://atlas.cid.harvard.edu/explore>.

5. Ver Amaral Filho (2018). 
seção, é feita uma revisão teórica da abordagem proposta aqui, apresentando-se a tese Prebisch-Singer e sua validade no contexto das CGVs. Na terceira seção, faz-se uma primeira análise dos dados a partir da perspectiva brasileira e da pauta de exportação e importação no comércio bilateral com a RPC, em que se constata a deterioraçáo dos termos de troca, a especializaçáo regressiva da pauta de exportaçáo e a diversificação da pauta de importação, composta por produtos de média e alta tecnologia. Na quarta seção, é analisada a demanda chinesa por soja, sua importância estratégica para o país e o modelo de importação, em que o país compra o produto de baixo valor agregado, processa internamente, agregando valor, e o utiliza na base da cadeia alimentar. Por fim, mas não menos importante, são feitas as considerações finais, em que compreendemos que o Brasil não conseguiu requalificar sua inserção nas CGVs, enquanto a RPC segue uma estratégia bem-sucedida, mas apresenta risco de dependência da soja brasileira.

\section{PREBISCH-SINGER E AS CADEIAS GLOBAIS DE VALOR}

Apesar de formulada na década de 1950, a tese Prebisch-Singer ainda permanece como uma ferramenta importante para interpretaçáo do comércio mundial a partir do método histórico estruturalista. Segundo Bielschowsky (2009, p. 175), esse método busca analisar as especificidades produtivas, os agentes sociais e institucionais da inserção internacional dos países latino-americanos e do Caribe, em sua condição de região periférica, e suas transformaçóes em médio e longo prazo. Os países periféricos são caracterizados por uma elevada desigualdade de renda e heterogeneidade produtiva, em que há o convívio de setores de elevada e baixa produtividade, em contraposição com os países centrais, os quais apresentam maior produtividade do trabalho e homogeneidade da estrutura produtiva de demanda (Dávila-Fernandez e Amado, 2015, p. 91). Bielschowsky (2020, p.7-8) esquematiza três pontos principais que diferenciam as características da periferia em relaçâao ao centro, que são: i) baixa diversidade produtiva e especializaçâo de bens primários; ii) grande heterogeneidade estrutural e oferta abundante de mão de obra com baixos rendimentos do trabalho; e iii) quadro institucional (Estado, tributação, empresariado, sistema financeiro e de inovação etc.) de composição de agentes pouco favoráveis à acumulaçăo de capital e progresso técnico.

Inicialmente proposto por Prebisch (1949), o conceito de centro e periferia está diretamente vinculado ao processo de Revolução Industrial do século XVIII, em que o centro se compốe das regióes nas quais as técnicas de produção capitalistas encontram-se mais avançadas, enquanto na periferia a produção permanece atrasada em relação à organização e à tecnologia. A diferença entre tais condiçóes é dada pela forma como o progresso técnico é difundido na economia mundial (Rodríguez, 2009, p. 81). Prebisch (1949, p. 83) assevera que os países centrais absorvem integralmente o fruto do progresso técnico, enquanto os países periféricos transferem parte do fruto do seu progresso técnico para os países 
centrais, pela composição da estrutura produtiva desses países e a diferença de elasticidade-renda dos bens primários e industrializados.

Na medida em que o centro é importador de bens primários, bens básicos com demanda inelástica, uma variação da renda do centro teria pouco impacto na variação da demanda desses bens. Por outro lado, a periferia, importadora de bens industrializados, teria uma demanda elástica, em que o aumento de sua renda promoveria um aumento da demanda por bens industrializados. Assim, com o progresso técnico, os ganhos de produtividade na periferia implicam a redução dos preços dos produtos primários, beneficiando diretamente os países do centro, importadores desses bens, promovendo-se a transferência dos ganhos gerados pelo progresso técnico da periferia para o centro (Cardoso, 2019, p. 113). Ao contrário do que pregavam os pressupostos da teoria clássica, a dinâmica internacional do comércio implica que os preços dos produtos industrializados apresentam um movimento de valorizaçáo com tendência de alta, e os ganhos gerados pelo progresso técnico não são equitativamente distribuídos, mas sim capturados primeiramente pelos consumidores das economias centrais, com a reduçấo dos preços dos produtos primários, promovendo-se a deterioraçáo dos termos de troca em relaçáo aos produtos manufaturados, enquanto no centro os ganhos de produtividade geram melhora na renda (Akyüz, 2020, p. 3).

Importante destacar que, ao se analisarem os ciclos ascendentes, quando há uma melhora dos termos de troca em favor da periferia, constata-se que essa melhora é temporária, porque, na fase descendente, a redução dos lucros ocorre de maneira desequilibrada entre centro e periferia, ao passo que as organizaçóes trabalhistas e sindicais no centro impóem uma maior rigidez à redução de rendas relativa, enquanto os países da periferia, tomadores de preço no mercado internacional, possuem condiçôes institucionais mais frágeis e menor capacidade de organização trabalhista. Isso faz com que a pressão para recuperação das taxas de lucro seja exercida sobre a periferia devido ao menor poder de resistir, na medida em que, quanto menor seja o impacto da redução das rendas, fruto da queda do dinamismo no centro, maior será a compressão das rendas na periferia. Dessa forma, se consolida a deterioração dos termos de troca nos ciclos econômicos do comércio entre países periféricos, exportadores de bens primários, e países centrais, exportadores de bens manufaturados (Silveira e Angeli, 2020, p. 73-74; Cardoso, 2019, p. 113-114).

Com a redução dos ganhos relativos dos países produtores de bens primários, a insuficiência dinâmica do sistema econômico periférico promove o desequilíbrio entre produtividade e investimentos realizados, ao passo que a oferta ilimitada de mão de obra, característica dessas regiôes, se concentra nas atividades de baixa produtividade e uma indústria nascente se vê incapaz de absorver essa mão de obra, formando-se o exército industrial de reserva (Cardoso e Reis, 2018, 
p. 9). Pode-se dizer que, assim, instaura-se a armadilha do subdesenvolvimento: a dinâmica colocada pela divisão internacional do trabalho não só mantém os países não industrializados sem os frutos do progresso técnico, como agrava sua condição periférica (Silveira e Angeli, 2020, p. 74).

Singer (1950, p. 482) sistematiza o papel ambíguo dos termos de troca no contexto dos países subdesenvolvidos. Segundo esse autor, ao mesmo tempo que o aumento dos preços internacionais dos produtos primários cria uma oportunidade de acumular recursos para o desenvolvimento industrial, tornam-se também mais atrativos os investimentos no próprio setor, dada a perspectiva de maximização dos lucros no período de alta. Na situação inversa, quando o preço dos bens primários encontra-se desaquecido, não existe a oportunidade para o acúmulo de recursos. Assim, os países da periferia não conseguem promover a sua industrialização em um boom porque as coisas andam bem e, quando as coisas andam mal, não conseguem acumular recursos para promover a industrialização.

A ideia de Singer é de que o progresso técnico se concentra na atividade industrial, permitindo às firmas do centro exercerem o poder de monopólio por um espaço de tempo, o que não ocorre na atividade primária, enquanto Prebisch destaca que a diferença de elasticidade-renda na procura mundial de produtos primários e manufaturados, associada à oferta ilimitada de mão de obra na periferia, gera uma pressão para baixo sobre os salários, promovendo a deterioração dos termos de troca, tendo os países que exportam produtos primários cada vez menos ganhos relativos em relação àqueles que exportam produtos industrializados (Dávila-Fernandez e Amado, 2015, p. 93).

No entanto, é necessário compreender o significado dessa tese para o século XXI, em um contexto no qual a dinâmica do comércio mundial passou por mudanças estruturais, especialmente a partir dos anos 1970. Nesse período, tem início o processo de financeirização das economias por meio da desregulação das contas de capitais, da liberalizaçáo dos fluxos e do crescimento dos investimentos transnacionais. Tal movimento é facilitado pelo avanço das novas tecnologias da área de telecomunicaçôes e motivado pela compressão das taxas de lucros nas economias centrais, levando à busca de outros territórios para recuperação dessas taxas. As formas utilizadas foram o desmembramento das políticas de bem-estar social e a busca de redução dos custos de transaçóes, com a integração vertical de operaçóes em outros países com algum nível de complexidade industrial e baixo custo de máo de obra, viabilizando menores custos. ${ }^{6}$ Dentro do mainstream, para esse movimento de liberalização e reorganização da dinâmica econômica é dado o nome de globalização. 
Nos países da América Latina, a adoção de tais políticas se intensifica na década de 1980 durante os governos de direita, mais ou menos radicais, e ditaduras militares alinhadas aos interesses dos Estados Unidos. Nesse contexto, é feita uma realocação dos principais centros fabris dos países centrais para regiōes de menor custo de mão de obra, inicialmente México e países do Sudeste Asiático, terceirizando-se a produção dos manufaturados por meio dos IDEs realizados pelas empresas transnacionais.? $\mathrm{O}$ resultado dessa reorganização produtiva para a DIT tem sido a manutençáo da dependência externa das economias do Sul (periferia) que promoveram políticas de liberalização, perdendo a autonomia das políticas nacionais de desenvolvimento. Esse arranjo produtivo é denominado de $\mathrm{CGV},{ }^{8}$ cuja organização representa a transferência de valor econômico extraído principalmente dos países do Sul para atender ao consumo no Norte (centro) (Suwandi, Jonna e Foster, 2019, p. 1). Portanto, dentro das CGVs, o papel dos países do Sul é o de fornecer baixos custos de produção e mão de obra, que permitam a máxima captura de valor realizada pelos IDEs dos países do Norte.

Cardoso e Reis (2018, p. 12-15) reforçam que, mesmo com tais transformaçóes pós-1970, do ponto de vista da distribuição da renda per capita, os países do centro e da periferia não apresentaram grandes mudanças no conceito da década de 1950, quando Prebisch e Singer formularam suas teorias. As autoras mostram que, apesar de os países periféricos terem passando a assumir atividades diretamente relacionadas à produçáo de manufaturados, a disparidade da renda com os países centrais ainda permanece acentuada. Isso mostra que os países periféricos assumem um papel intermediário na produção dos manufaturados, mas o valor gerado ainda é capturado pelas economias centrais, o que nos leva a compreender que a relação estabelecida antes pela dualidade entre produção de bens primários e bens manufaturados, nas CGVs está colocada na forma de participaçáo dentro de atividades de alto valor adicionado ou não. Isso significa que o ponto-chave para a relação centro-periferia se estabelece no grau de complexidade das estruturas produtivas e comerciais, em vez da simples dualidade setorial. Apesar disso, vale salientar que a produtividade agrícola ainda se destaca com maior diferencial entre os dois grupos (Cardoso e Reis, 2018, p. 22-27).

Utilizado em diferentes trabalhos, o marco da literatura de estudo empírico da tese Prebisch-Singer é dos autores de Grilli e Yang (1988), que formulam indicadores para uma análise do período 1900-1986 e confirmam a hipótese da tendência de deterioração dos termos de troca, encontrando um resultado de $0,6 \%$ ao ano (a.a.). Ademais, existe uma extensa literatura que discute o método, como Ocampo e Parra-Lancourt $(2003 ; 2010)$, que mostram a existência de períodos de alta dos preços das commodities, mas afirmam que, em uma perspectiva de longo prazo, a deterioração dos termos de troca se confirma; Serrano e Pinilla (2011), que confirmam

7. Ver Dunning (2001).

8. Ver Humphrey (2004). 
a deterioração de forma não contínua e em estágios; assim como Harvey et al. (2010) e Arezki et al. (2014), que, mesmo utilizando diferentes métodos, encontram uma tendência linear, com quebra estrutural e em ciclos, e concluem que existe uma maior volatilidade nos preços das commotidies do que nos bens industrializados. Por sua vez, Prado, Torraca e Silva (2014) indicam que, mesmo na primeira década dos anos 2000, com a alta dos preços, ainda se verifica a deterioração dos termos de troca.

No entanto, Gruss (2014, p. 5-6) ressalta que diversos trabalhos fazem uma aproximação sobre a deterioração dos termos de troca com a variação dos preços das commodities. A cesta de exportação de um país não necessariamente é composta somente por bens primários, e as importações não necessariamente se constituem apenas de bens industrializados. Quando o autor utiliza o Net Commodity Price Index (NCPI), método formulado por Deaton e Miller (1996), para a Colômbia e o Uruguai, observa que, apesar de, para a Colômbia, os resultados permitirem tal aproximação, no Uruguai apresenta-se uma diferença de $20 \%$ positivo para $15 \%$ negativo, dado que o país é um grande importador de petróleo cru, o qual teve uma valorizaçáo de quase quatro vezes no período 2003-2013.

Assim, entende-se a importância e a validade atual da tese Prebisch-Singer, segundo a qual, mesmo que países da periferia tenham promovido algum nível de industrialização, condição necessária para diminuir as disparidades existentes, ainda permanecem majoritariamente como fornecedores de matéria-prima e produtos de baixa complexidade, como acontece na América Latina. Nesse sentido, a literatura tem dado conta de problematizar a situaçáo da região a partir de diferentes métodos e abordagens. No entanto, o que chama a atenção, e é o foco deste trabalho, é a situação específica da relação entre Brasil e China nessas duas primeiras décadas do século XXI, em que houve uma intensificação das relaçôes da América Latina com a RPC. Dessa forma, buscamos compreender a evolução dos termos de troca e as características do comércio estabelecido entre os dois países, compreendendo as possibilidades e limitaçóes da tese Prebisch-Singer quanto às CGVs.

\section{RELAÇÕES COMERCIAIS BRASIL-CHINA}

O Brasil éo país da América Latina que mantém a maior participação nas importaçóes chinesas da região, com $54,12 \%$ do valor em 2018 , o equivalente a 3,4\% do PIB brasileiro. ${ }^{9}$ Isso significa um aumento de mais de seis vezes na participação do Brasil na balança comercial chinesa nos últimos anos, que passou de 0,6\% em 2000 para $3,8 \%$ em 2018. ${ }^{10}$ Assim, desde 2009, a China ocupa a primeira posição entre os

9. Dados da UN Comtrade (2020) e do World Bank (2020).

10. Disponivel em: <https:/atlas. cid.harvard.edu/explore?country=43\&product=undefined\&year=2017\&tradeDirection= import\&productClass=HS\&target=Partner\&partner=undefined\&startYear=1995> . 
destinos das exportaçóes brasileiras em valor, com $27 \%$, posição que antes era dos Estados Unidos, segundo destino desde entâo, com menos da metade $(11,14 \%)$ da participação chinesa. Por outro lado, as importaçóes brasileiras da RPC cresceram ainda mais de forma relativa, evoluindo de 2,2\%, em 2000, para 19\% em 2018.

Conforme apontado na tabela 2, os três principais produtos da balança comercial brasileira são minério de ferro e derivados, petróleo cru e refinado e soja, que em 2000 somavam 11,87\%, e passaram a compor 29,87\% em 2018, enquanto os mesmos produtos na balança comercial chinesa, pelo lado da importação, passaram de 8,3\% para 13,3\%. Além disso, a participação do Brasil na comercialização de produtos da agricultura ganhou mais espaço no mercado mundial, passando de $2,5 \%$ para $4,8 \%$ em 2013 . Desde entâo o país mantém uma participação aproximada de $4,6 \%$ sofrendo pequenas oscilaçóes.

TABELA 2

Participação dos três principais produtos de exportação brasileira nas balanças comerciais do Brasil e da China

(Em \%)

\begin{tabular}{|c|c|c|c|c|c|c|}
\hline & \multicolumn{2}{|c|}{$\begin{array}{l}\text { Balança comercial brasileira } \\
\text { (exportação) }\end{array}$} & \multirow{2}{*}{$\begin{array}{c}\text { Variação } \\
\text { 2000-2018 }\end{array}$} & \multicolumn{2}{|c|}{$\begin{array}{l}\text { Balança comercial chinesa } \\
\text { (importação) }\end{array}$} & \multirow{2}{*}{$\begin{array}{c}\text { Variação } \\
\text { 2000-2018 }\end{array}$} \\
\hline & 2000 & 2018 & & 2000 & 2018 & \\
\hline Minério de ferro e derivados & 6,4 & 10 & 57 & 0,6 & 2,6 & 355 \\
\hline Petróleo cru e refinado & 1,5 & 8,6 & 466 & 7 & 9,2 & 34 \\
\hline Soja & 4 & 11,5 & 182 & 1 & 1,5 & 66 \\
\hline Total & 13 & 29 & 151 & 8,3 & 13,3 & 60 \\
\hline
\end{tabular}

Fonte: UN Comtrade (2020)

Elaboração dos autores.

Obs.: A participação relativa é da balança comercial total, incluindo produtos e serviços.

Nota-se que, no que se refere à participação do Brasil na DIT, o país aprofundou sua inserção externa como fornecedor de commodities, e de forma excessivamente concentrada em três produtos que representam um terço de todo o seu valor de exportação, com destaque para petróleo cru e refinado e para a soja, com variação de $466 \%$ e $182 \%$, respectivamente. Enquanto isso, a China aumentou sua demanda pelos principais bens exportados pelo Brasil, com destaque para o minério de ferro e derivados que apresentou uma variação de 355\%.

Diante disso, o importante debate posto por Prebisch e Singer nos ajuda a analisar a situação da relação entre Brasil e China, especificamente no contexto em que a América Latina como um todo ganhou relevância na alta dos preços das commodities, consequência da demanda da China, que assume a posição de principal parceiro comercial da regiáo. Como colocado anteriormente, com a queda dos preços, poucos países da regiáo permaneceram mantendo superavit 
comercial com a RPC, entre eles o Brasil. No entanto, tal análise parece insuficiente para compreender a complexidade das relaçôes comerciais entre os dois países a partir da vulnerabilidade externa e do progresso técnico.

Quando analisados termos de troca e saldo comercial (gráfico 2) entre o Brasil e a RPC, no período de 2000 a 2019, é possível observar que, mesmo com um saldo comercial positivo e crescente para o Brasil, com pequenas oscilaçóes, os termos de troca do lado brasileiro apresentam uma clara tendência de deterioração. A razáo disso pode ser compreendida quando analisada a pauta do comércio bilateral. Os principais produtos exportados nos anos 2000 eram de baixa complexidade, principalmente commodities como soja, minério de ferro e tabaco, sendo $80 \%$ do valor das exportaçóes distribuídos em doze itens. As principais exportaçôes da China para o Brasil eram produtos de média e alta complexidade, sendo que os mesmos $80 \%$ de valor estavam diluídos em 346 itens, de dispositivos cristais líquidos (liquid crystal display - LCD) e placas-mães (mother boards) a unidades de disco magnético para disco rígido. Em 2019, 80\% do valor das exportaçóes brasileiras para o país concentraram-se em quatro itens - soja, óleos brutos de petróleo, minério de ferro e seus concentrados e pastas químicas de madeira -, enquanto as importaçóes brasileiras provenientes da RPC perfizeram os seus $80 \%$ em mercadorias cujos valores foram distribuídos em 646 itens de média e alta tecnologia. ${ }^{11}$

GRÁFICO 2

Saldo comercial (valor FOB' US\$) e termos de troca (eixo secundário) Brasil-China

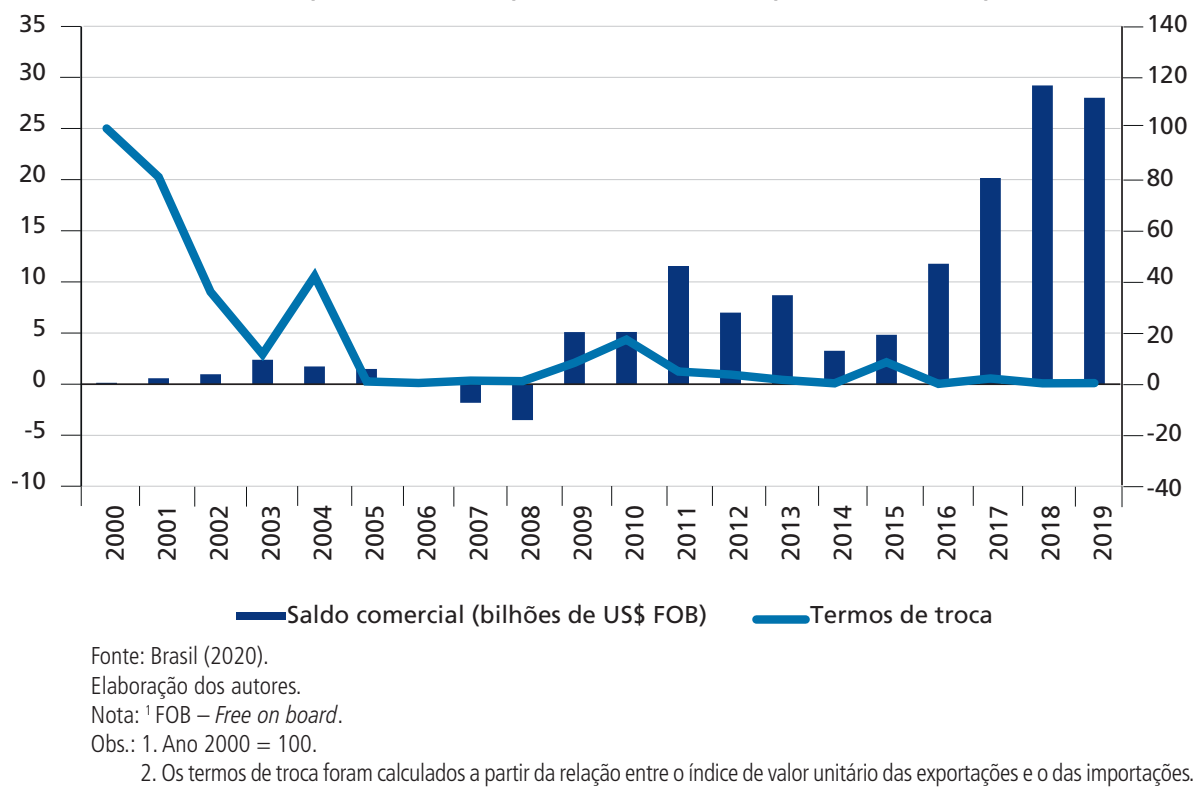

11. As especificações dos itens de exportação e importação seguem o padrão de Nomenclatura Comum do Mercosul (NCM). 
Portanto, pode-se dizer que as relaçóes comerciais entre o Brasil e a RPC, do ponto de vista brasileiro, apesar de apresentarem um saldo comercial com tendência crescente nos últimos cinco anos (2014-2019), decorrente do crescimento mais acelerado das exportaçōes do que importaçōes, ${ }^{12}$ se concentra em poucos produtos, de baixo valor agregado e alta volatilidade de preços. Por seu turno, as importações brasileiras da China são dispersas e diversificadas em diferentes tipos de produtos de média e alta tecnologia, com alto valor agregado, que, por tais características, podem exercer poder de monopólio sobre a oferta e os preços dos produtos. Isso significa que o Brasil tem que exportar um volume cada vez maior de seus produtos para conseguir manter sua capacidade de importação, visto que os produtos exportados pelo Brasil têm um valor relativo cada vez menor.

Assim, é possível confirmar a tese Prebisch-Singer no que confere à deterioração dos termos de troca nesse caso do comércio bilateral dos países, o qual, na perspectiva histórico-estruturalista, ajuda a fortalecer a dependência do Brasil em relação à RPC, que concentra os ganhos gerados pelo progresso técnico. Nesse sentido, Bernal-Meza (2018, p. 85) e Cano (2012, p. 841-842) concordam que a posição da China na DIT, com alta produtividade e câmbio desvalorizado, fez com que o país estabelecesse a clássica relação centro-periferia com a América Latina, importando bens primários da regiáo e exportando manufaturados, assim como ocorre na relação da região com os Estados Unidos e com outros países do centro dinâmico do sistema capitalista, o que traria uma imagem ruim para a RPC.

A RPC e a Índia são os países que têm a maior participação da mão de obra, mas exportam a maior parte da sua produção ${ }^{13}$ para os Estados Unidos, onde é consumida. Isso nos mostra como a produção e o consumo estão separados. $\mathrm{O}$ valor adicionado na cadeia de valor das commodities é desproporcionalmente atribuído às atividades econômicas nos países mais ricos do centro, embora a maior parte do trabalho ocorra no Sul (periferia). Os economistas neoclássicos, e até algumas correntes menos tradicionais, justificam os ganhos diferenciais de renda dos países do Norte (centro) e do Sul à produtividade. Porém, como demonstrado por Suwandi, Jonna e Foster (2019, p. 12-16), muitas vezes a produtividade dos países do Sul chega a ser maior do que a dos países do Norte, e a diferença reside na discrepância entre a remuneração dada às horas trabalhadas. Isso porque é permitida a livre mobilidade internacional do capital e se restringe fortemente a livre mobilidade do trabalho. O que leva os autores a concluírem que a RPC não está em uma posição diferente, visto que há uma expropriação

12. Apesar da queda dos preços das commodities a partir de 2011, o crescente valor das exportações brasileiras é sustentado pelo volume crescente desses produtos.

13. Segundo os dados de 2018 da United Nations International Trade Statistics Database (UN Comtrade), a RPC exporta cerca de $18,41 \%$ e a Índia 15,21\% da sua produção para os Estados Unidos. 
absoluta do valor dos trabalhadores chineses, semelhante ao que se verifica em outros países do Sul.

Não é possível afirmar categoricamente a posição da China dentro do comércio internacional como uma nação periférica ou central. A complexidade estabelecida nas CGVs exige uma análise crítica e mais detalhada. Porém, no que concerne à sua relação especificamente com o Brasil, não há dúvidas de que pode ser enquadrada como uma relação centro-periferia, tendo em vista o padrão do comércio bilateral entre os países.

Nas cadeias globais, o comércio das três principais commodities agrícolas, trigo, soja e milho, é controlado pelo Grupo ABCD, as empresas estadunidenses Archer Daniels Midland (ADM), Bunge e Cargill, e a francesa Louis Dreyfus Company, que atuam no transporte e processamento dos produtos, comercializados como alimentos, combustível ou ração animal, a depender das condiçóes do mercado, qualidade e preço. Em 2016, esse grupo controlava mais de $70 \%$ do mercado mundial do setor agrícola (Chemnitz et al., 2017, p. 26). Para Holt-Giménez e Shattuck (2011) e McMichael (2009), essas companhias estão por trás do que eles chamam de regime alimentar corporativo, em que as figuras centrais do acesso aos alimentos estão nas grandes empresas agroalimentares monopolistas, que lideram as cadeias de fornecimento de insumos aos produtores agrícolas e a distribuição desses produtos em escala mundial.

No entanto, a China National Cereals, Oils and Foodstuffs Corporation (COFCO), maior empresa de alimentos da China, vem ganhando espaço nesse mercado. Em 2014, a estatal chinesa adquiriu o controle da trading holandesa Nidera e de parte da divisão agrícola da Noble Group, duas empresas que atuam na aquisição e comercialização da soja brasileira, o que fez com que a COFCO aumentasse sua participação no mercado mundial, passando a fazer parte do ABCD, agora ABCCD (Escher e Wilkinson, 2019, p. 673-674). Nesse contexto, buscamos aprofundar a análise a partir do estudo de caso da soja brasileira e da sua importância para a estratégia chinesa.

\section{BRASIL, A CHINA E A SOJA}

A soja é um dos principais produtos de exportação brasileira e o principal produto exportado para a RPC. No período de 2000 a 2018, passou de $4 \%$ para $11 \%$ no valor total das exportaçôes, enquanto a China aumentou ainda mais a sua participação, de $8,54 \%$ para $67,48 \%$ de toda a soja exportada pelo Brasil. O produto pode ser comercializado in natura ou processado, como seus subprodutos, que são o farelo e óleo. ${ }^{14} \mathrm{~A}$ soja e seus subprodutos são utilizados para ração

14. Segundo a Associação Brasileira das Indústria de Óleos Vegetais (Abiove), $1 \mathrm{~kg}$ de soja in natura processada rende $770 \mathrm{~g}$ de farelo e $205 \mathrm{~g}$ de óleo. 
animal, outros óleos, biodiesel, além de servirem como base para outros produtos alimentícios e industrializados.

O principal incentivo fiscal à expansão da produção e exportação de soja no Brasil vem da Lei Complementar no 87/1996 (Lei Kandir), ${ }^{15}$ que isenta os exportadores de produtos in natura do pagamento do Imposto sobre Circulação de Mercadorias e Serviços (ICMS). Isso levou ao rápido crescimento da comercialização da soja, em detrimento do produto processado. Assim como os outros bens primários, a soja também passou por um processo de alta nos seus preços no início dos anos 2000, em parte provocada pelo aumento da demanda chinesa. Nesse contexto, Gazzoni e Dall'Aganol (2018, p. 75) indicam que isso levou ao que seria a quarta fase ${ }^{16}$ de sua expansão, tendo o cultivo da soja alcançado os estados do Pará, Rondônia e Roraima, além de áreas no sudoeste do estado do Mato Grosso. No início dos anos 2000, o território destinado à soja era de 13,96 milhóes de hectares, que evoluiu para 36,94 milhóes de hectares ${ }^{17}$ na safra 2019/2020, o que significa um crescimento aproximado de duas vezes o território de Honduras. A consequência disso é que o país passou a produzir um terço de toda a soja no mundo desde 2017. ${ }^{18}$

O mercado de soja concentra $80 \%$ da produção em três países, Argentina, Brasil e Estados Unidos, que consomem apenas $26 \%$ da sua produção, destinando o resto para exportação. É interessante notar que, apesar de esses serem os principais produtores, a RPC é quem lidera o processamento da soja, com mais de 85 milhôes de toneladas, seguida pelos Estados Unidos, com 56,93 milhóes, Argentina, com 40,56 milhóes, e Brasil, com 42,52 milhóes, como apresentado no gráfico 3. Isso significa que o Brasil exporta a maior parte da sua produçấo in natura, enquanto a China, apesar de produzir aproximadamente apenas 5\%, é responsável por quase $30 \%$ de todo o processamento.

15. Disponivel em: <http://www.planalto.gov.br/ccivil_03/leis/lcp/lcp87.htm>.

16. A primeira fase acontece na região Sul, nas décadas de 1960 e 1970; na segunda fase, ocorre sua expansão para a região Centro-Oeste, no final da década de 1980 e começo da década de 1990. A terceira fase acontece no início dos anos 2000, com a expansão para a região denominada Matopiba (Maranhão, Tocantins, Piaú e Bahia).

17. Disponivel em: <https://www.conab.gov.br/info-agro/safras/serie-historica-das-safras>.

18. Segundo dados do United States Department of Agriculture (USDA) e da Companhia Nacional de Abastecimento (Conab). 
GRÁFICO 3

Soja produzida e processada - países selecionados (2019)

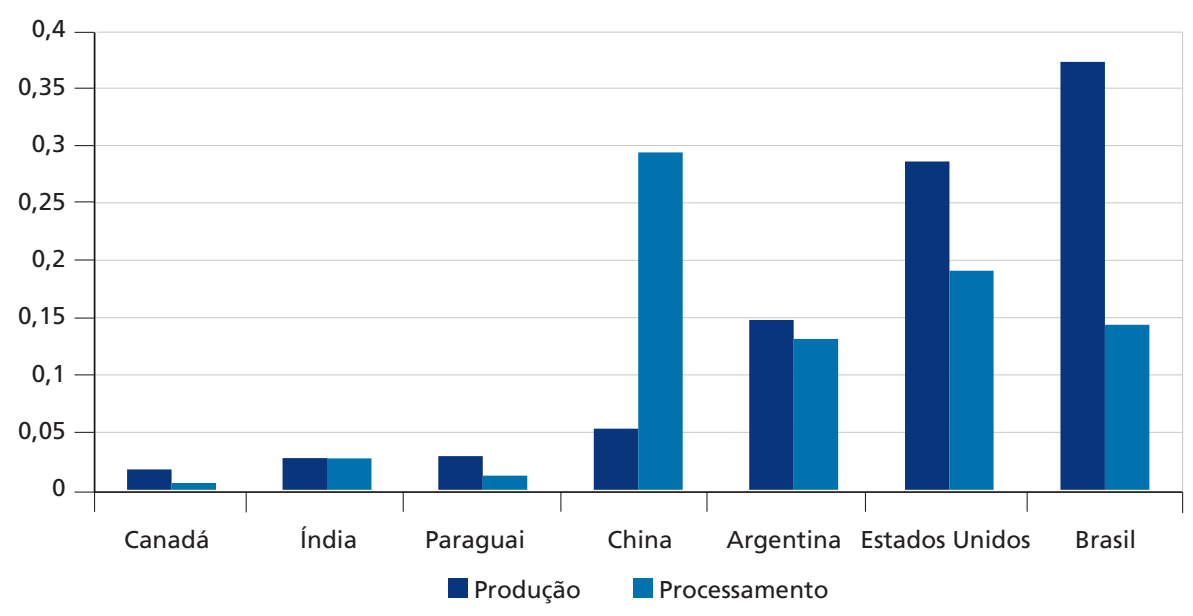

Fontes: FAO (2020); USA (2020).

Elaboração dos autores.

Os dados nos mostram que o Brasil é um grande exportador de soja in natura e a RPC uma grande compradora. Quando observado o comércio bilateral entre os dois países, constata-se que praticamente toda a soja brasileira (99\%) comprada pela China é in natura, ${ }^{19}$ que também é a principal compradora da soja brasileira, consumindo mais de $60 \%$ de toda a sua produção. Do mesmo modo que a produção brasileira triplicou, de 38,4 milhóes de toneladas em 2000 para 115 milhóes de toneladas em 2019, a China aumentou em 37 vezes o seu consumo do produto brasileiro, de 1,78 milhão de toneladas para 66 milhóes de toneladas no mesmo período. ${ }^{20}$ Com isso, existe uma forte correlação entre a expansão da produção de soja no Brasil e a demanda chinesa, construindo-se um cenário em que o Brasil cultiva soja para vender para a China, que compra mais da metade das suas exportaçóes, e a China tem o país como principal fornecedor, responsável por $77,9 \%$ de toda a soja importada em 2018. Dados esses números, é possível dizer que existe uma dependência mútua entre os dois países, visto que o Brasil não tem alternativa para quem vender o que produz, e a China não tem de quem comprar o que consome.

19. Além do Brasil, a importação dos outros dois principais fornecedores, Estados Unidos e Argentina, também é $99 \%$ in natura.

20. A base de dados pode ser consultada no Ministério da Economia brasileiro, disponível em: <http://comexstat.mdic. gov.br/pt/home>; no Instituto Nacional de Estadística y Censos de la República Argentina, disponível em: <https:// comex.indec.gob.ar/>; e no Observatory of Economic Complexity, disponível em: <https://oec.world/en/profile/ country/usa>. 


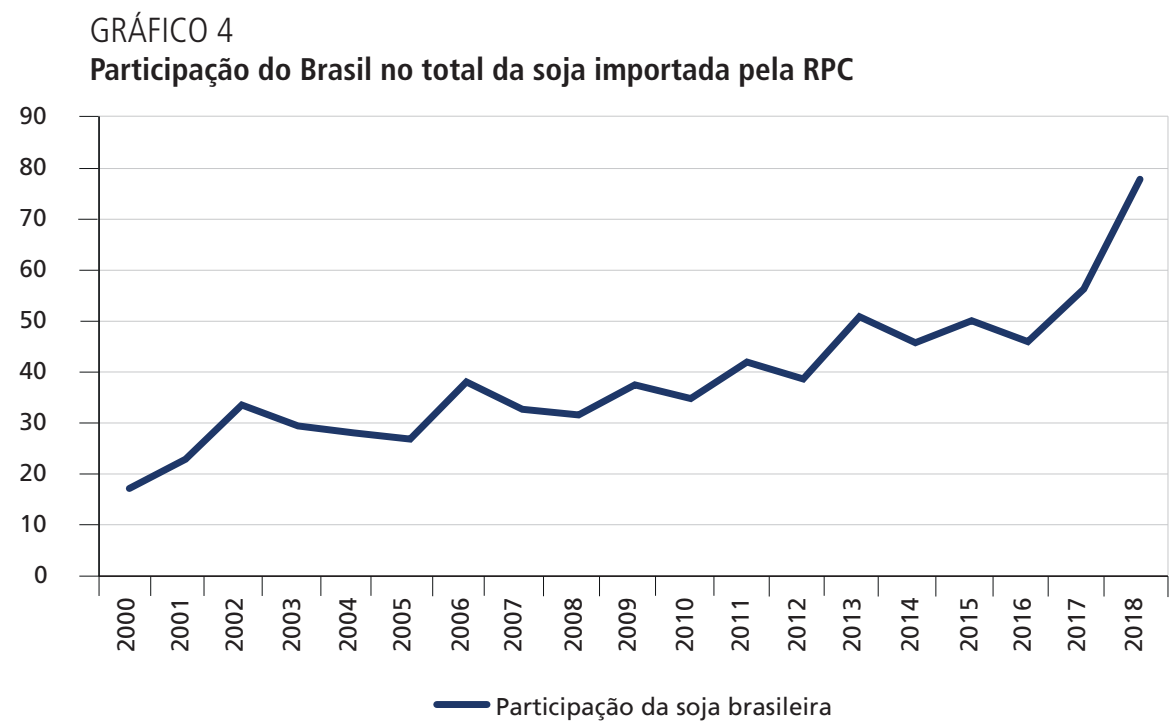

Fonte: Brasil (2020); NBSC (2020). Disponivel em: <http://comexstat.mdic.gov.br/pt/geral>; <http://www.stats.gov.cn/tjsj/ ndsj/2005/indexeh.htm>.

Elaboração dos autores.

Vale destacar que, com a alta dos preços de alimentos, ${ }^{21}$ os chineses buscaram criar algumas alternativas, como a compra de terras em países da África para transformar em campos de soja, milho, arroz e trigo, entre outros produtos agrícolas. No entanto, como mostra o trabalho de Brautigam (2015), a iniciativa foi superestimada, teve resultado em poucos investimentos concretos, sem se conseguir resolver a questáo. Outras iniciativas, no Oriente Médio e com a Associação de Naçôes do Sudeste, vislumbram uma saída alternativa, que até o momento não tem sido efetiva, como apontado anteriormente.

A importância da soja para a China vem com o crescimento do poder de compra desde os anos 1990, que provocou uma série de mudanças estruturais no consumo de produtos agrícolas e no crescimento da demanda por alimentos proteicos e processados, devido ao aumento da elasticidade-renda (FAO, 2013, p. 17). Esse efeito foi estudado também por Gale e Huang (2007, p. 4), que observaram uma mudança gradual no padrão de dieta chinês, tradicionalmente dominada por cereais e vegetais, e que foi substituída aos poucos por uma dieta de alimentos ricos em gorduras e mais calóricos, com o aumento da renda da população. Nesse sentido, Zhang e Diao $(2020$, p. 8) destacam que a urbanização também faz com que as pessoas consumam cada vez mais produtos processados em detrimento de produtos in natura, ou seja, com uma transição do campo 
para a cidade e o rápido aumento da renda, há uma mudança no consumo de alimentos, movimento esse que ocorreu na China no período de 1990 e 2018, quando a população urbana passou de $26,41 \%$ para $59,58 \% .^{22}$

Quando observado o consumo per capita de carnes, peixes, produtos lácteos, açúcar e óleos vegetais ( $\mathrm{kg} / \mathrm{hab} . / \mathrm{ano})$, é possível constatar o crescimento constante no período de 1990 a 2018, em que o consumo foi de 31,26 kg para 150,87 kg per capita a.a., enquanto o consumo de cereais teve uma redução de $176,36 \mathrm{~kg}$ para $145,95 \mathrm{~kg}$, confirmando a mudança. ${ }^{23}$ Com exceção do açúcar, todos os demais produtos utilizam a soja processada na sua produção, que majoritariamente é utilizada para compor a raçăo ${ }^{24}$ de porcos, aves, ovinos, bovinos, peixes e a produção de leite. Esses números se tornam ainda mais relevantes porque a China tem um quarto da população mundial, com uma renda per capita que evoluiu de US\$311,88 a.a., em 1990, para US\$ 9.001,00 a.a. em 2018.

\section{GRÁFICO 5}

Consumo per capita de carnes, peixes, produtos lácteos, açúcar e óleos vegetais (kg/hab./ano) versus PIB per capita (US\$) na RPC (1990-2018)

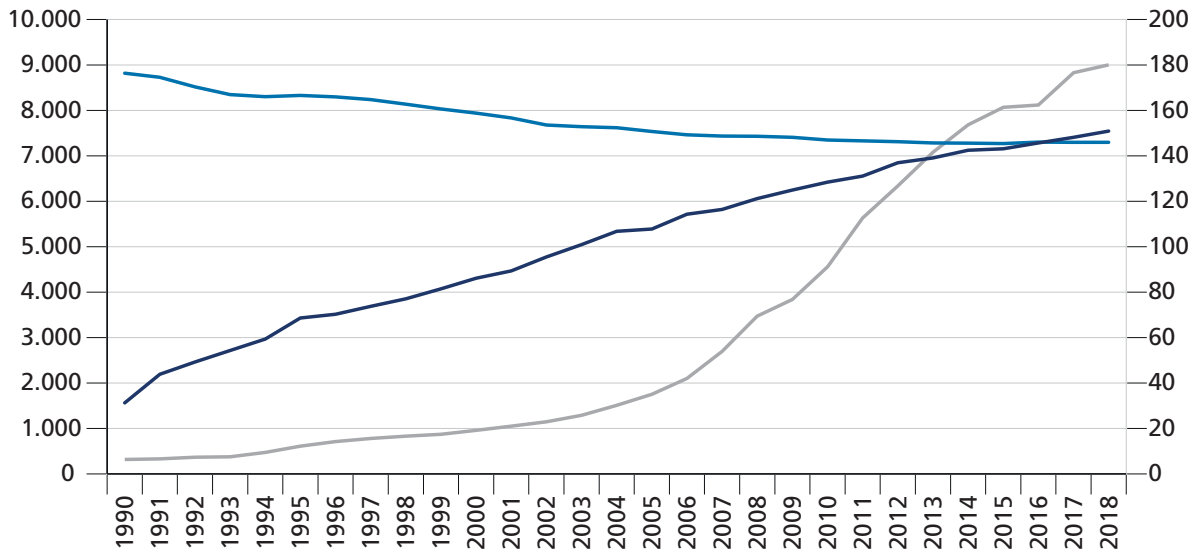

- Carne, peixes, produtos lácteos, —Cereais _ PIB per capita (US\$) açúcar + óleos vegetais

Fontes: OECD e FAO (2018); World Bank (2020).

Elaboração dos autores.

Outro importante destaque é o fato de o território chinês possuir apenas $8 \%$ das terras aráveis do mundo, o equivalente a 122 milhóes de hectares. Caso o país decidisse plantar toda a soja que importou em 2019, precisaria de 54 milhóes de

22. Disponível em: <http://www.stats.gov.cn/enGliSH/>.

23. Disponível em: <http://www.stats.gov.cn/enGliSH/>.

24. As rações animais são produzidas a partir do farelo da soja, o principal ingrediente proteico das rações animais (aves, suínos, bovinos e peixes), apresentando bom valor nutricional. 
hectares, ou seja, $44 \%$ de sua área agrícola, algo inviável, uma vez que a China concentra o uso dessas terras para a produção de cereais básicos, como arroz, milho e trigo, e essas áreas vêm produzindo cerca de $95 \%$ de seu consumo doméstico. Além disso, sua área agrícola é utilizada para produtos de maior valor agregado relativo à soja, como hortaliças, frutas, granja de suínos, aves e ovos, além do tabaco, intensivos em mão de obra, em vez de intensivos em terra, como a soja (Huang e Yang, 2017, p. 5). Nesse contexto, a soja é importada para ser processada pela mão de obra chinesa, garantindo ocupação e renda para a população que permanece no campo, e a farinha é utilizada na base de ração de animais que vão compor esse novo padrão alimentar. No entanto, a excessiva concentração de soja brasileira $(80,9 \%)^{25}$ pode ser uma questão para sua segurança alimentar.

Em uma perspectiva de médio ou longo prazo, Huang et al. (2017, p. 2939) indicam que a RPC poderá explorar novas áreas, como a Ucrânia e a Europa Oriental, como já vem fazendo aos poucos na Ásia Central e no continente africano. Além disso, o país pode melhorar sua produção agrícola a partir de investimento em infraestrutura e tecnologia. Em relação aos outros produtores de relevância, os Estados Unidos, além de terem uma relaçáo política conturbada com o país, têm alguma volatilidade na produção de soja, intercambiada com o milho para o mercado doméstico, utilizado para fabricação de etanol, dependendo do valor e da segurança no mercado futuro. A Argentina tem uma política de processar em torno de $80 \%$ da soja internamente, o que talvez não interesse à RPC. Além disso, segue uma exportação média de pouco mais de 7,2 milhōes de toneladas de soja in natura para o país asiático entre 2015 e 2019, o que significa menos de $10 \%$ das importaçóes totais. Sem se considerar que a última previsão para a safra de 2020 aponta para uma colheita menor do que a de $2019 .{ }^{26}$

\section{CONSIDERAÇÕES FINAIS}

Ao se analisarem as relaçóes comerciais da RPC com os países da América Latina, foi possível verificar uma crescente importância do país para a região. Observando-se os dados, é possível constatar que, desde o início dos anos 2000 até o final dessa segunda década, a RPC estreitou os laços com a regiáo, tanto como importadora de bens primários como exportadora de produtos manufaturados. O caso brasileiro, aprofundado no decorrer deste trabalho, mostra que, nesse período, mesmo com a valorização dos preços das commodities, o país intensificou a especialização produtiva regressiva, ao passo que diversificou ainda mais suas importaçóes de bens de média e alta tecnologia da RPC.

25. Os Estados Unidos e a Argentina que são o segundo e terceiro maiores fornecedores da China, têm 9,88\% e 3,88\%, respectivamente, de participação. Disponível em: $<$ https://oec.world/en/profile/country/chn/\#trade-products $>$. 26. Disponível em: <https://comex.indec.gob.ar/>. 
Diante disso, mesmo com um saldo comercial positivo, o Brasil apresenta tendência de deterioração dos termos de troca no período analisado e dependência da volatilidade dos preços internacionais para o planejamento do seu desenvolvimento. Isso tem implicado, cada vez mais, a necessidade do país de exportar um volume maior de seus principais produtos, a fim de poder manter sua capacidade de importaçáo no comércio bilateral com a RPC. Nesse contexto, se estabelece a dupla armadilha dos termos de troca, como discutido por Singer (1950), dado que o Brasil intensificou sua produção de soja e as exportaçóes para a China, sem conseguir requalificar a qualidade de sua inserção, e concentrando ainda mais sua pauta de exportaçáo. Isso nos leva a classificar a relaçẫo Brasil-China como uma clássica relação centro-periferia.

Por seu turno, ao se analisar o caso da soja brasileira, a RPC assume uma estratégia de aquisição do produto in natura, processando internamente, gerando o valor no próprio país, na medida em que promove a ocupação da mão de obra e gera renda para a população rural, sem ter o uso intensivo da terra, que é um fator escasso no país. Enquanto isso, utiliza a terra disponível para produtos de maior valor agregado, intensivos em mão de obra, mantendo emprego para a população no campo, que ainda representa aproximadamente $40 \%$ da população, o equivalente a 558 milhóes de pessoas em 2019. No entanto, se destaca o fato de o Brasil ter uma importância significativa nesse comércio, chegando a fornecer cerca de $78 \%$ de toda a soja importada pela RPC, o que configura um cenário sem alternativas para os chineses no curto prazo.

Dessa forma, é possível constatar que o Brasil reforçou sua dependência estrutural na sua inserção na DIT durante o período analisado, na medida em que passa a concentrar ainda mais suas exportaçóes em três principais produtos, sem diversificar ou complexificar sua pauta. No comércio bilateral com a RPC, apresenta uma intensa deterioraçáo dos termos de troca, enquanto o seu parceiro comercial estabelece uma estratégia de médio e longo prazo, ao passo que importa o produto de baixo valor agregado, gera valor internamente, e o utiliza como base da sua cadeia de produção e consumo, sustentando o seu desenvolvimento dentro das CGVs.

\section{REFERÊNCIAS}

AKYÜZ, Y. The commodity-finance nexus: twin boom and double whammy. Revista de Economia Contemporânea, v. 24, n. 1, 2020.

AMARAL FILHO, J. do. Prebisch-Cepal: revisitando o "Manifesto de Havana". Economia e Sociedade, v. 27, n. 1, p. 29-59, 2018.

ANDRADE, I. O.; NARETTO, N. A.; LEITE, A. W. A dinâmica das relaçôes econômicas entre Brasil e China: uma análise do período (2000-2015). Boletim de Economia e Política Internacional, n. 21, set./dez. 2015. 
AREZKI, R. et al. Testing the Prebisch-Singer hypothesis since 1650: evidence from panel techniques that allow for multiple breaks. Journal of International Money and Finance, v. 42, p. 208-223, 2014.

BERNAL-MEZA, R. China and Latin America relations: the win-win rhetoric. Journal of China and International Relations, 2016.

Dos aportes teóricos latinoamericanos de relaciones internacionales y su utilización por el pensamiento chino contemporáneo: los casos de Prebisch y Escudé. Revista de Estudios Sociales, v. 64, p. 75-87, 2018.

BIELSCHOWSKY, R. Sesenta años de la Cepal: estructuralismo y neoestructuralismo. Revista Cepal, 2009.

. Do "manifesto latino-americano" de Raul Prebisch aos dias de hoje: 70 anos de estruturalismo na Cepal. Revista de Economia Contemporânea, v. 24, n. 1, 2020.

BLACK, C. Tendência, quebra estrutural e persistência dos choques no preço da soja de 1960 a 2014. Indicadores Econômicos, v. 43, n. 3, p. 9-26, 2016.

BRASIL. Exportaçáo e importaçáo geral. Brasília: Ministério do Desenvolvimento, Indústria e Comércio Exterior, 2020. Disponível em: <http:// comexstat.mdic.gov.br/pt/geral>. Acesso em: 9 jul. 2020.

BRAUTIGAM, D. Will Africa feed China? Oxford: Oxford University Press, 2015.

CANO, W. A desindustrialização no Brasil. Economia e Sociedade, v. 21, p. 831-851, 2012.

CARDOSO, F. G. Nove clássicos do desenvolvimento econômico. [s.l.] Paco Editorial, 2019.

CARDOSO, F. G.; REIS, C. F. de B. Centro e periferia nas cadeias globais de valor: uma interpretaçáo a partir dos pioneiros do desenvolvimento. Revista de Economia Contemporânea, v. 22, n. 3, 2018.

CHEMNITZ, C. et al. Konzernatlas: daten und fakten über die agrar-und lebensmittelindustrie - 2017. [s.l.]: [s.n.], 2017.

CHESNAIS, F. A mundializaçáo do capital. São Paulo: Xamã, 1996.

UN COMTRADE - UNITED NATIONS INTERNATIONAL TRADE STATISTICS DATABASE. UN Comtrade database. New York: UN Comtrade, 2020. Disponível em: <https://comtrade.un.org/>. Acesso em: 10 jul. 2020.

DÁVILA-FERNÁNDEZ, M.; AMADO, A. Thirlwall's law and the Prebisch-Singer hypothesis: an assessment of the dynamics of terms-of-trade in a balance-of-paymentsconstraint growth model. Economia e Sociedade, v. 24, n. 1, p. 87-119, 2015. 
DEATON, A.; MILLER, R. International commodity prices, macroeconomic performance, and politics in Sub-Saharan Africa. Princeton: Princeton University Press, 1995.

DUNNING, J. H. The eclectic (OLI) paradigm of international production: past, present and future. International Journal of the Economics of Business, v. 8, n. 2, p. 173-190, 2001.

ESCHER, F.; WILKINSON, J. A economia política do complexo soja-carne Brasil-China. Revista de Economia e Sociologia Rural, v. 57, n. 4, p. 656-678, 2019.

FAO - FOOD AND AGRICULTURE ORGANIZATION. Crop prospects and food situations. [s.l.]: FAO, Apr. 2008.

FAO, 2013.

Statistical yearbook: world food and agriculture - 2013. Rome:

. FAOSTAT. Rome: FAO, 2020. Disponível em: <http://www.fao.org/ faostat/en/\#data/HS>. Acesso em: 25 ago. 2020.

GALE, H. F.; HUANG, K. Demand for food quantity and quality in China. [s.l.]: United States Department of Agriculture, 2007.

GAZZONI, D. L.; DALL'AGNOL, A. A saga da soja de 1050 a.C. a 2050 d.C. Brasília: Embrapa, 2018.

HOLT-GIMÉNEZ, E.; SHATTUCK, A. Food crises, food regimes and food movements: rumblings of reform or tides of transformation? The Journal of Peasant Studies, v. 38, n. 1, p. 109-144, 2011.

GRILLI, E. R.; YANG, M. C. Primary commodity prices, manufactured goods prices, and the terms of trade of developing countries: what the long run shows. The World Bank Economic Review, v. 2, n. 1, p. 1-47, 1988.

GRUSS, B. After the boom: commodity prices and economic growth in Latin America and the Caribbean. [s.l.]: International Monetary Fund, 2014.

HARVEY, D. I. et al. The Prebisch-Singer hypothesis: four centuries of evidence. The Review of Economics and Statistics, v. 92, n. 2, p. 367-377, 2010.

HUANG, J. et al. The prospects for China's food security and imports: will China starve the world via imports? Journal of Integrative Agriculture, v. 16, n. 12, p. 2933-2944, 2017.

HUANG, J.; YANG, G. Understanding recent challenges and new food policy in China. Global Food Security, v. 12, p. 119-26, 2017.

HUMPHREY, J. Upgrading in global value chains. Geneva: ILO, 2004. 
HYMER, S. Empresas multinacionais: a internacionalizaçáo do capital. Rio de Janeiro: Graal, 1983.

IMF - INTERNATIONAL MONETARY FUND. Direction of Trade Statistics (Dots). New York: IMF, 2020. Disponível em: <https://data.imf. org/?sk=388dfa60-1d26-4ade-b505-a05a558d9a42>. Acesso em: 22 jul. 2020.

MCMICHAEL, P. A food regime genealogy. The Journal of Peasant Studies, v. 36, n. 1, p. 139-169, 2009.

MEDEIROS, C. A. D.; CINTRA, M. R. V. P. Impacto da ascensão chinesa sobre os países latino-americanos. Brazilian Journal of Political Economy, v. 35, n. 1, p. 28-42, 2015.

OCAMPO, J. A. Commodity-led development in Latin America. International Development Policy, v. 9, p. 51-76, 2017.

OCAMPO, J. A.; PARRA-LANCOURT, M. Los términos de intercambio de los productos básicos en el siglo XX. Revista de la Cepal, 2003.

The terms of trade for commodities since the mid-19th century. Revista de História Econômica, v. 28, n. 1, p. 11-43, 2010.

OECD - ORGANISATION FOR ECONOMIC CO-OPERATION AND DEVELOPMENT; FAO - FOOD AND AGRICULTURE ORGANIZATION. OECD agriculture statistics. Paris: FAO, 2020. Disponível em: <https://doi. org/10.1787/d4bae583-en>. Acesso em: 16 ago. 2020.

PELLA, A. F. C. Relaçóes comerciais entre Brasil e China a partir dos anos 2000: uma análise do conteúdo tecnológico. Revista de Estudos Sociais, v. 21, n. 42, p. 138-160, 2019.

PRADO, L. C. D.; TORRACA, J. F.; SILVA, J. C. A. L. e. Um novo olhar sobre um antigo debate: a tese de Prebisch-Singer é, ainda, válida? Rio de Janeiro: UFRJ, 2014. Disponível em: <https://www.ie.ufrj.br/images/IE/TDS/2014/ TD_IE_003_2014.pdf>.

PREBISCH, R. O desenvolvimento econômico da América Latina e seus principais problemas. Revista Brasileira de Economia, v. 3, n. 3, p. 47-111, 1949.

RODRÍGUEZ, O. O estruturalismo latino-americano. Rio de Janeiro: Civilização Brasileira, 2009.

SERRANO, R.; PINILLA, V. The terms of trade for agricultural and food products, 1951-2000. Revista de História Econômica, v. 29, n. 2, p. 213-243, 2011.

SILVEIRA, M. G.; ANGELI, E. Uma reflexão sobre o início da Cepal e seu contexto. Revista Economia Ensaios, v. 34, n. 2, 2020. 
SINGER, H. W. The distribution of gains between investing and borrowing countries. The American Economic Review, v. 40, n. 2, p.473-85, 1950.

SUWANDI, I.; JONNA, R. J.; FOSTER, J. B. Global commodity chains and the new imperialism. Monthly Review, v. 70, n. 10, p. 1-24, 2019.

TAVARES, M. C. A retomada da hegemonia norte-americana. Brazilian Journal of Political Economy, v. 5, n. 2, 1985.

USA - UNITED STATES OF AMERICA. Department of Agriculture. Foreign agricultural service. Washington: United States Department of Agriculture, 2020. Disponível em: <https://www.fas.usda.gov/>. Acesso em: 30 jun. 2020.

WORLD BANK. World Bank open data. Washington: World Bank, 2020. Disponível em: <https://data.worldbank.org/>. Acesso em: 27 jul. 2020.

ZHANG, Y.; DIAO, X. The changing role of agriculture with economic structural change: the case of China. China Economic Review, v. 62, p. 101504, 2020.

\section{BIBLIOGRAFIA COMPLEMENTAR}

MORAIS, I. N. de Políticas de fomento à ascensão da China nas cadeias de valor globais. In: CINTRA, M. A. M.; SILVA FILHO, E. B. da; PINTO, E. C. China em transformaçáo: dimensóes econômicas e geopolíticas do desenvolvimento. Brasília: Ipea, 2015.

NBSC - NATIONAL BUREAU OF STATISTICS OF CHINA. 2002 a 2019: China statistical yearbook. Beijing: NBSC, 2020. Disponível em: <http://www. stats.gov.cn/tjsj/ndsj/2019/indexeh.htm>. Acesso em: 26 jul. 2020.

PREBISCH, R. Commercial policy in the underdeveloped countries. The American Economic Review, v. 49, n. 2, p. 251-273, 1959.

WANG, D.; TOMEK, W. G. Commodity prices and unit root tests. New York: [s.n.], Apr. 2004. p. 19-20. 